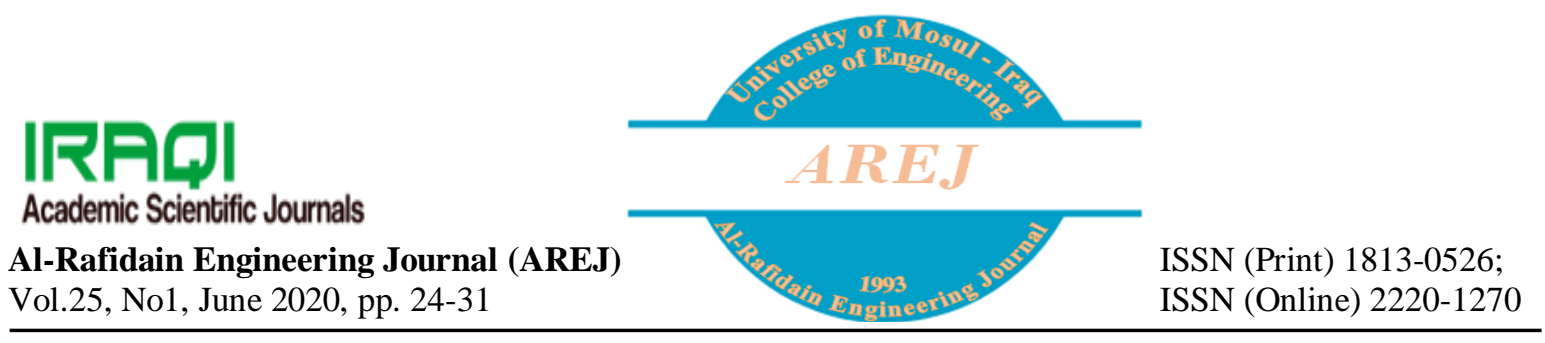

\title{
A Survey Paper on Six Phase Induction Motor Drive
}

\author{
Myasar Salim Alattar* \\ myasaralattar@uomosul.edu.iq
}

\author{
Ahmed N. Alsammak ${ }^{* *}$ \\ ahmed_alsammak@uomosul.edu.iq
}

\footnotetext{
* Mechatronics Engineering Departement, Collage of Engineering, University of Mosul

** Electrical Engineering Departementand, Collage of Engineering, University of Mosul
}

Received: 10/1/2020

Accepted: $16 / 5 / 2020$

\begin{abstract}
This paper introduces different topics about six phase induction motor drives. It describes a different methods used for analyzing and representing induction motor model, by using (d-q-o) modelling and ( $x-y$-o) some papers discussed motor model and its characteristics, controlling speed of motor and efficiency improvement. some techniques of control strategy such as (direct torque control, field oriented control, indirect field oriented control and sliding mode control etc. will be present to improve motor operation.as well this paper will present some techniques for voltage generation used to drive motors, some methods are implemented for this purpose depending upon quasi voltage generation, pulse width modulation, and space vector pulse width modulations etc are also discussed.
\end{abstract}

\section{Keywords:}

Six phase induction motor, multi-phase induction motor, voltage source inverter (VSI), PWM, SVPWM, multi-phase drive.

\section{INTRODUCTION (10 PT)}

Due to their, reliability low Cost robustness and low maintenance simple operation Three-phase induction machines considered as a basis for industrial application and ac drive in our life. However, the development of power electronics device and circuits as well as improving the characteristic of signal processing systems lead to growth in use these ac machines drive systems, the drawback of induction machine where the mission of variable speed control needed is eliminate due to developed in control systems. Like modern techniques of field oriented vector control, direct torque control etc.Growing power demand imposes the need to improve system performance, especially when power supply and power electronics switches are limited, from this point the idea of using PWM and SPWMtechniques, new machine design criteria and the use of harmonic current injection is created, In last three decades a wide interest has been highlighted on renewable energy sources like wind turbine and converters connected with it, in addition to industrial application including Electric ship propulsion, sub marine ship. Where increased power ratings, reliability of operation, redundancy and efficiency are required. A multiphase motor drives have been suggested to overcome these application to get a properate benefits like (lower ripple in torque, lesser total harmonics distortion in DC side, greater reliability, and well power sharing can, the main advantage of multi-phase is decreasing the stress on power electronics device unlike the threephase inverter. due to current reduction in power semiconductor because increasing number of phases addition number of power switchs areadded with low cost. On the opposing, an increasing current sensors number, firing circuits, extra power source. now adayback-to-back inverters are the base of $\mathrm{AC}$ drives. which classically consist of more than two -level, and a three-phase motor. A combination of multi phase machines having more than three phase machines 
with buck inveter increasesystem reliability gained be "lessen torque osscilation, refinement fault tolerance, and appropriate power distribution for each phase. However, studies of multiphase generators, motorsincluding five-phase, six-phase and more than,are achived and puplished.

\section{Literature view}

Mohamed A. Abbas, and others fabricated a prototype six phase variable speed drive consisting of transistorize inverter and control circuit .as they built a model they made up of two three phase winding induction motor with phase shift electrical angle 30 degree. Finally laboratory model gave an experimental results, for supporting them the researchers create a mathematical model in (d-q-o) axis to compare between the results was gained.These project shows that harmonics orders in the six-phase drives are $(6 \mathrm{k}+1, \mathrm{k}=1,3,5,-$ have no influence on the air-gap flux ,thusno torque ripple or loss in rotor are create, where the amplitudes of current harmonics deals with voltage source system output, hence they restricted by the stator resistance and leakage inductances between the stator phases. Other side of study in paper investigate the techniques to control the amplitudes of these harmonics current. All these investigations have been studied under different conditions using digital computer. System parameters used in these simulations have been derived directly from prototype was built. [1]

Alfredo R. Muñoz, and Thomas A. Lipo, designed and implemented dual stator winding induction machine (DSIM). The project was a typical squirrel-cage rotor with dual stator windings having an unlike number of poles for each one. The aim for building this model with this characteristic is to improve ability to operate at different speeds (low and zero), Then it help the researchers to implement speed sensor less controller systems to enhance the degree of flexibility for conventional control strategy used in ac drives. There are two control strategy introduced in this paper with simulated motor, the results were gained for prototype, viewing very good performance. Particularly for both scalar constant $\mathrm{V} / \mathrm{Hz}$ and vector control, figure below shown the V/f operation at stand still [2] Figure (1) shows Constant V/Hz operation at standstill.

Akpama, E. J. implement a model of dual stator squirrel cage induction motor sharing a one rotor (DSIM) representing by ( Iabc) (Ixyz)current vectorsas suitable form for sub marin application depening on propulsion theory this motor build to repjaceset of conventional (three phase Induction motor ) by on motor to gain the following advantages increase the reliability of operation, increase the efficiency by reducing the losses, reduced the pulsating torque and enhanced the total motor torque ,improved usage of control strategy for exchange speed and enhanced over all operation figure (2) phase motor replaced two three phase motor show one six [3]

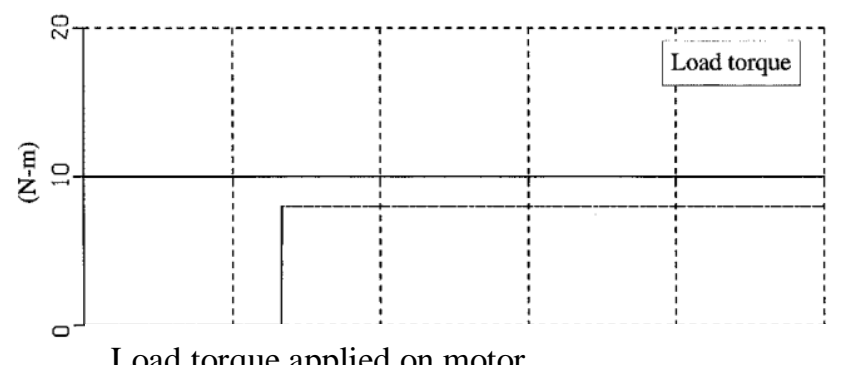

Load torque applied on motor

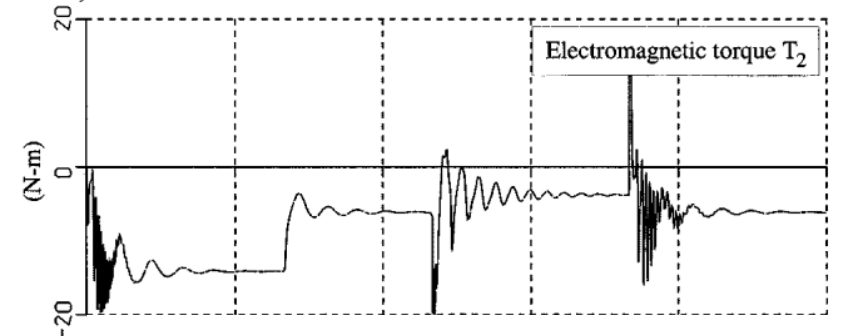

Electromagnetic torque generates by second winding

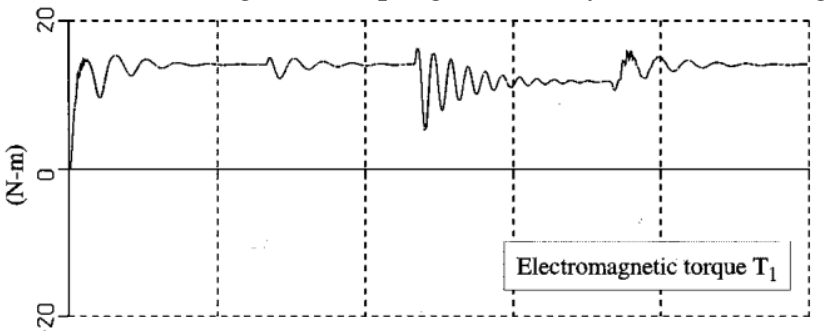

Electromagnetic torque generates by first winding

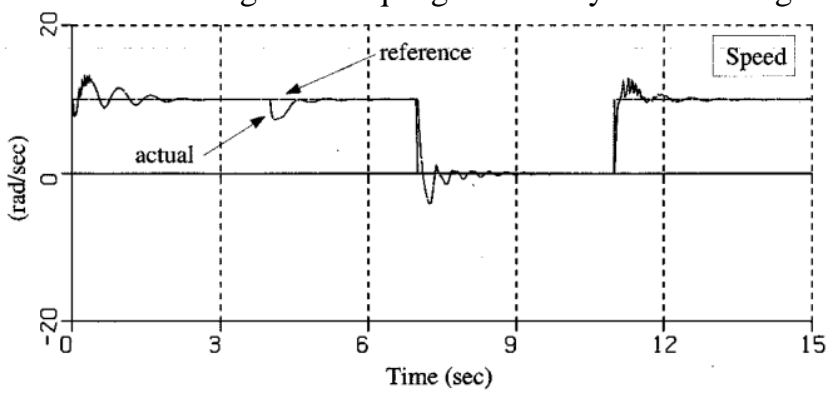

Figure (1) Constant V/Hz operation at standstill.

ArchanaNanoty and A. R. Chudasama modeled a prototype six phase induction motor with double three phase winding having 30 degree phase shift by this modulation it can be eliminate third harmonics current so no need to inject this rank of harmonics, due to last 
modulation it can be gained a torque equal to 1.6 times that of three phase induction. Theygained and shows the following benefits of a developed prototype six-phase induction motor : 1 enhanced reliability which means if one inverter fails, the motor continues to run. 2. Due to eliminate third harmonics by 30-degree phase shift losses reduced thus efficiency improved. 3 . The other advantage by phase shift modulation is reduced the dc bus inverter by $50 \%$ by using 30 degrees' phase displacement, 4 . They used vector control without using sensors as cheap control method [4]

Hang Seng Che, and others introduced a practical method to balance the dc-link midpoint driving a system containingtwo cascaded asymmetrical six phase induction machine operation for both state generation and motoring. By applied series connection of machine it can be used two sets of inverters which leads to reduce dc link voltage by $50 \%$ of same value used for conventional motor also $d v / d t$. Is reduced. to eliminate use of PWM strategy in low voltge motor they make difference angle between the two separated neutral points. by this modification system is now appropriate in remote offshore wind Farms connected with HVDC system, where there is a limitation in rising dc link voltage may lead rise a cost of system. These limitation overcomes by improving controlling the power sharing between the machines through using the " $\mathrm{x}-\mathrm{y}$ wave form to destabilize the winding currents this operation iplement using a suitable a dc-link voltage balancing controller. This method added an extra degrees of freedom in operation state, which are available in multiphase machines only, [5]

Atif Iqbal, Mohd. Ayyub and M Arif Khan founded a six phase voltage source inverter driving both six phase induction motor or cascaded two three phase induction motor they introduced analytical model using vector space decoupled vector (VSD) that analyze both machine and inverter in d-q-x-y system. To get a good wave form voltage as output of inverter they used (SVPWM) techniques for (VSI). In this study the converter generates two fundamental voltages with different frequency as a method of control system to get a voltage with low harmonics order. so they conclude that two separate modulation schemes (d-q and $\mathrm{xy}$ ), which independently produce a pure sinusoidal wave form by inverter output fig bolow shown the out put voltage supplied by inverter with its spectrum are united together to realize this requirement. The required inverter rating of the proposed configuration is evaluated. There is a saving of three inverter legs (additional three legs of
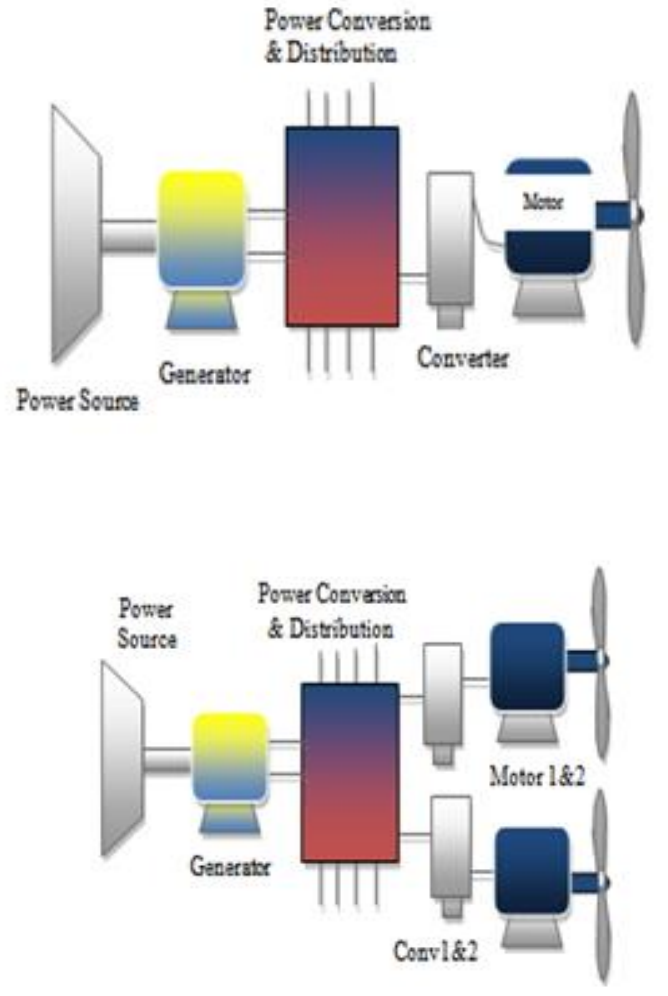

Figure (2) show one six phase motor replaced two three phase motor

inverter supplying three-phase motor is not needed) with the proposed configuration but with an expense of $5.4 \%$ or more increase in its rating. The viability of the proposed scheme is proved using simulation results. [6]. figure (3) Space Vector PWM for a Six-Phase VSI Supplying a Six- phases induction motor shows the THD wave form and of inverter voltage with its spectrum analyzing

R. Gregor1, F. Barrero, S. Toral1 and M.J. Durán. By modelling and implementing six phase induction motor depending on theoretical analysis they got all characteristics machine (speed/ torque) then they show the following advantage of multi-phase system compared to the conventional 3-phase, "lessening rotor harmonic losses, the power switches tension, the torque ripple; or the total harmonics distortion pleased of the DC-link side all of that enhanced the system trustworthiness". However, six phase induction machine are founded from many years but there many fields not studied yet, this paper established different experimental analysis 
situation for one of the most talented multi-phase results, [7]

R. S. Miranda, C. B. Jacobina, A. M. N. Lima implement and tested a six phase induction motor under dissimilar kinds of faults happened in voltage source inverter they present the dynamiceffects on motor under these conditions. If a fault state (open or short circuit) happened a state of unwanted Operation create affecting torque oscillations at low frequency leads to severe harms of the system. However, multiphase system

allows us to advance various approaches for postfault operation to rise reliability of the System. Paperconsidered a useful study to create an idea to imrove the fault accepting control strategy and fault analysis. It confirms the importance ducking the fault state directly through protective control action. [8]
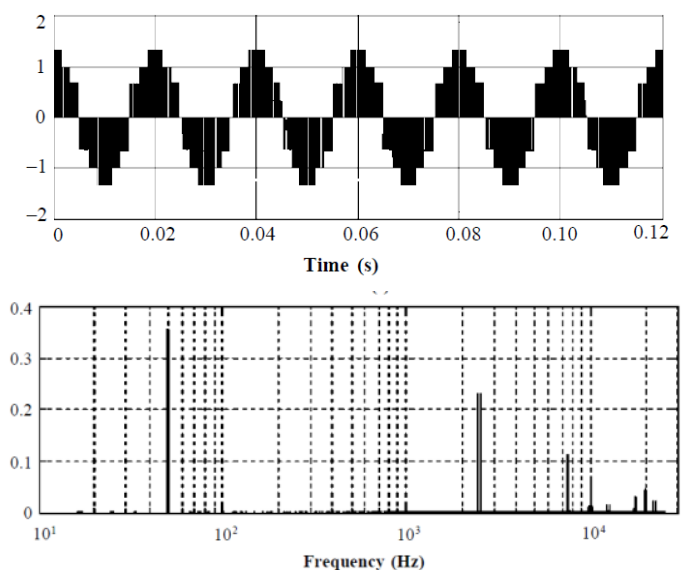

Figure (3) six phase motor voltage waveform and THD With its spectrum

Hang Seng Che, and others suggested the use of asymmetries and dead-time compensation $\mathrm{x}-\mathrm{y}$ current control where at "deadtime compensation, a resonant regulator advanced in the anti-synchronous reference frame gave the finest act "however all outcomes supported by experimental results. By using PI controllers shown in figure (4)they get usefulness of asymmetry compensation depending on the synchronous reference frame. For getting Complete compensation for all the probable cases researchers derived the double -PI controllers (i.e., couples for synchronous and antisynchronous reference frames). [9] Figure (4) shows "Dead-time compensator for a three-phase machine using a resonant controller in the synchronous $(\mathrm{d}-\mathrm{q})$ reference frame. And figure (5) shows Dead-time compensator for an asymmetrical six-phase machine using a resonant controller in the anti-synchronous $(\mathrm{x}-\mathrm{y})$ reference frame. "[9]

Mohamed I. Abdelwanis and F. Selim designed and executed a PID controller to achieve (V/f) closed control system for six phase induction motor as driver of centrifugal pump. They used mat lab Simulink environment to achieve this system, pulse width modulation (PWM) also studied as a technique for generating voltage supplied to motor. However, after building model and tested it they prove the following fact. 1-using PWM techniques for controlling and generate supply voltage from inverter leads to lessen total harmonic distortion for current and voltage 2- six-phase PWM inverter is more efficient compared to double three phase inverter to drive six phase induction motor .3- six phaseinduction motor is appropriate machine for applied Sensor less control method to control the speed of motor .4- multi phase motor has more reliability in many applications compared to conventional motor. [10]

SanjeevikumarPadmanaban and others introduced a theoretical model of asymmetrical six phase induction motor for achieving the suggested field oriented control system (FOC) to enhanced machine performance they used many three phase voltage source inverter to carry out power sharing between them to supply motor each (VSI) of four three level of voltage waveform. Where they are each two inverter represent a group connected to the end of stator winding. The procedure of power sharing has three variables gives three grades of liberty in control, figure (6) shows the diagram of this algorithm. First and second variables share voltages between two converters for dual threephase with open circuit stator windings. The last variable represents the current between two open circuit stator windings. [11]

JACEKLISTWAN,KRZYSZTOFIEŃKOWSKI .create a control system to enhance the performance of six phase induction motor. After building a machine model they try to regulate and control speed of motor to achieve that a sliding mode control system using direct field oriented control (SMCDFOC) method to gain a smooth and good accuracy. They conclude the following fact 1electromagnetic torque deals with the state of the driver. 2- The value of the stator currents depend on the state at which drive operate.3- for all experiment state of the drivere, the overshoots and oscillations in wave form eliminate for the controlled electromagnetic variables [12] 


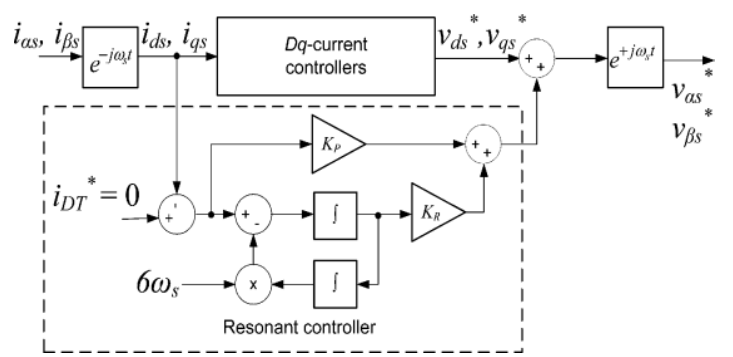

Figure (4) Dead-time compensator for a three-phase machine using a resonant controller in the synchronous $(\mathrm{d}-\mathrm{q})$ reference

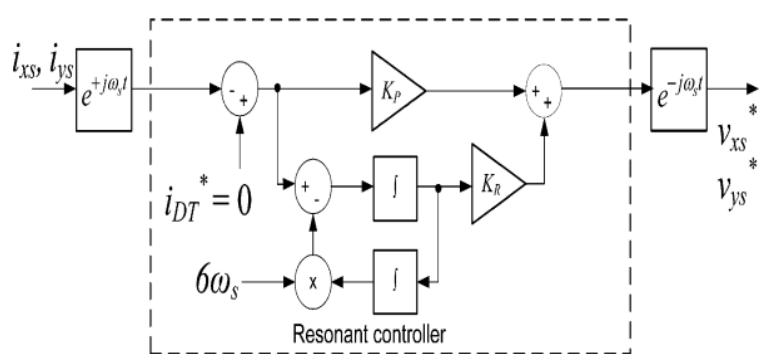

Figure (5) Dead-time compensator for an asymmetrical six-phase machine using a resonant controller in the anti-synchronous $(\mathrm{x}-\mathrm{y})$ reference

Reza Kianinezhad and others. Displayed a novel prototype for stationary and dynamicaly analysis of dual winding multi-phase induction motor with 60 electrical degrees between them. Where this model can be used to compute instantaneous parameters of motor (torque/ current /flux). they generalized it to overcome more than conventional three depending on rotating synchronous reference. This new model is appropriate for testing conditions. "Test-rig" with a regular six phase induction motorwith its drive connected on a forty-two-volt dc bus. [13] .

Daniel Nahum Zmood, and Donald Grahame Holmes. Implemented a control scheme for compensation to build a system gives zero steady state error for any parameter wanted to regulate it for six phase induction motor. the system depends on (synchronous frame equivalent) .in this paper current regulating takes as an example to prove this strategy where all results gained from simulation model have been supported experimentally using both analog and digital techniques. [14]

M.J. Duran, I. Gonzalez-Prieto1, N. Rios1, F. Barrero .one of the most important problem of motor is fault state (open or short circuit) and how it machines behaves after that happened and how it restores itself to normal conditions researchers in this paper showed a strategy to detect these type of fault depending on states that are particularized before treatment phase currents. In six phase induction motor it can be used vector space decomposition formula to reveal fault. Figure (6) shows a vector space decomposing then by combaining $x-y$ currents componenet with to hysteresis band, it can have sensed the open circuit state and find its position exactness this way has and fester than applying unoriginal phase-current-depending on. Combination of vector space decomposition scheme and error tolerance mechanism, they get a system like conventional VSD-based control strategies. the suggested system may be used with more than three phase drivers to build highperformance fault-tolerant strategy with no need added Hardwar, this type of control has Simplicity, fast detection, assured in addition to an easy switch from pre- to post-fault situations of driver. [15]

G.K. Singh, V. Pant, Y.P. Singh. Modeled a universal six-phase machine model it built using reference frames with 30 electrical

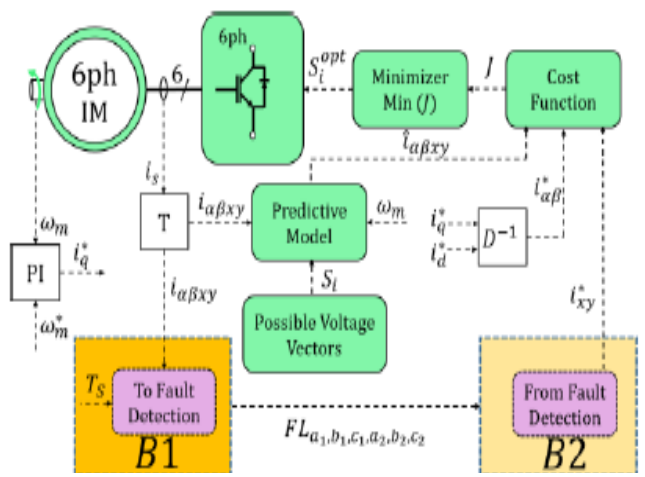

Figure (6) MPC scheme and fault detection method

degree phase shift The machine supplied from voltage source inverter with pulse width modulation. They tested machine performance under normal conditions with six-step and PWM voltage source inputs. From the results that have been gained researchers conclude that make 30 degrees_shift between the stationary winding sets energized by multi step voltage source convertor. A lesson in torque osscilations leads to a soft operation of drive. That also leads to reduce a generating heat in rotor due to reduction in rotor currents but the drawback caused by this angle is rising in stator current then rising losses of stationary side, however stator winding cooling control is simpler than the rotor temperatureusing this type of drivers, another type of connection 
where angle lies between ( 0 or 60 ) degree but the 30 degree still the better. researchers used six phase inverter over conventional type due to low torque ripple so no noise and mechanical stress on the motor is happened, less voltage source harmonics, researchers explain reference frame used to modeled which is very helpful to implement different category of control schemes tpimplement closed loop process. Also they presented the impact of mutual leakage coupling between the two stationary winding motor. [16]

Federico Barrero and others established a control strategy for enhancement six phase induction motor. They used Predictive control scheme, researchers used modern microprocessors for computing power in this control strategy also they introduced a different type of the unoriginal predictive control strategy, called OSPC, the last type is suggested to regulate current faster of VSI-driven six phase induction machines the strategy in this case is similar to that method used in conventional type which depend on using a quality function which is valued based on those predictions over a restricted disappearing prospect. However OSPC method gives the flexibility for implementing two voltages vectors withen specimen time, to given that better act in real-time applications than CPC systems. For all Simulation results gained from researchers an experimental results confirm supporting them. [17]

\section{Conclusion:}

Six phase induction motor drives are one of the multi-phase induction machine, now a day many applications have been depended on them. controlling on these type of motor has been taken an interested by researchers to modified them or improve their performance. One of these method to regulate motor operation deals with designing their winding by making a specific angle can be eliminating current harmonics, pulsating torque,ripple, give machine more degree of freedom and reliability. also these type of machine like conventional motor can be use (V/f) to control their speed. Different type of control strategy used to improve motor operating such as (DTC, SMC, FOC, and INFOC). Model predictive control scheme used for detecting and locating fault problem (both open and short circuit). Using these type of motor has many advantages for voltage source inverter especially lessen the stress on power semiconductor device, reduce the power rating for converter switches, and gives more flexibility for inverter

\section{REFERENCES}

[1]MOHAMED A. ABBAS, MEMBER, IEEE, ROLAND CHRISTEN, AND THOMAS $M$. JAHNS, 1984 'Six-Phase Voltage Source Inverter Driven Induction Motor' IEEE TRANSACTIONS ON INDUSTRY APPLICATIONS, VOL. IA-20, NO. 5, SEPTEMBER/OCTOBER 1984J. Yli-Kaakinen and T. Saramak, "A Systematic Algorithm for the Design of Lattice Wave Digital Filters with ShortCoefficient Wordlength",IEEE Transactions on Circuits and Systems-I,Vol. 54, Issue: 8, pp. 1838 - 1851, Aug. 2007.

[2]Alfredo R. Muñoz, Member, IEEE, and Thomas A. Lipo, Fellow, IEEE . 'Dual Stator Winding Induction Machine Drive'IEEE TRANSACTIONS ON INDUSTRY APPLICATIONS, VOL. 36, NO. 5, SEPTEMBER/OCTOBER 20001369.

[3]. Department of Elect/Elect Engineering, Cross River University of Tech., Calabar/Nigeria Corresponding Author: Akpama, E. J.' Six Phase Induction Motor Modelling For Submarine Application 'IOSR Journal of Electrical and Electronics Engineering (IOSR-JEEE) e-ISSN: 2278-1676,p-ISSN: 2320-3331, Volume 13, Issue 1 Ver. IV (Jan. - Feb. 2018), PP 61-66 www.iosrjournals.org DOI: 10.9790/16761301046166www.iosrjournals.org61

Communication Systems",USA,ISBN 10: 0131465112, Prentice Hall,2004.

[4]Archana Nanoty1,*, A. R. Chudasama2 'Control of Designed Developed Six Phase Induction Motor 'International Journal of Electromagnetics and Applications 2012, 2(5): 77-84 DOI: 10.5923/j.ijea.20120205.01

[5]Hang Seng Che, Emil Levi, Fellow, IEEE, Martin Jones, Mario J. Duran, Wooi-Ping Hew, Member, IEEE, and NasrudinAbd. Rahim, Senior Member, IEEE 'Operation of a Six-Phase Induction Machine Using Series-Connected Machine-Side Converters ' IEEE TRANSACTIONS ON INDUSTRIAL ELECTRONICS, VOL. 61, NO. 1, JANUARY 2014.

[6] Atif Iqbal*, Mohd. Ayyub** and M Arif Khan*** 'Space Vector PWM for a Six-Phase VSI Supplying a Six-Phase and a Three-Phase Series-Connected Machine '2009 The Icfai University Press. All Rights Reserved.

[7]R. Gregor1, F. Barrero1, S. Toral1 and M.J. Durán21 Electronic Engineering Departments E.S.I., University of Seville Camino de losDescubrimientos s/n, 41092 Sevilla (Spain) 'Realization of an Asynchronous Six-Phase Induction Motor Drive Test-Rig'

[8] R. S. Miranda1 C. B. Jacobina2 A. M. N. Lima2 'MODELING AND ANALYSIS OF SIX- 
PHASE INDUCTION MACHINE UNDER FAULT CONDITION '978-1-4244-33704/09/\$25.00 @ 2009 IEEE

[9]Hang Seng Che, Emil Levi, Fellow, IEEE, Martin Jones, Wooi-Ping Hew, andNasrudinAbd. Rahim, Senior Member, IEEE IEEE TRANSACTIONS ON POWER ELECTRONICS, ' Current Control Methods for an Asymmetrical Six-Phase Induction Motor Drive ' VOL. 29, NO. 1, JANUARY 2014407

[10]Mohamed I. Abdelwanis Electrical engineering department Kafrelsheikh University Mohamed.soliman4@eng.kfs.edu.eg , F. Selim Electrical engineering department KafrelsheikhUniversityKafrelsheikh,Egypthegaz2 009@yahoo.com ‘ A Sensorless Six-Phase Induction Motor Driving a Centrifugal Pump System' 2017 Nineteenth International Middle East Power Systems Conference (MEPCON), Menoufia University, Egypt, 19-21

[11] SanjeevikumarPadmanaban a, *, Gabriele Grandi a, FredeBlaabjergb,JosephOlorunfemiOjo c, Patrick William Wheeler d 'Power sharing algorithm for vector controlled six-phase AC motor with four customary three-phase voltage source inverter drive 'Engineering Science and Technology, an International Journal journal homepage: http://www.elsevier.com/locate/jestch [12]JACEKLISTWAN,KRZYSZTOF

PIENKKOWSKI' 'SLIDING-MODE DIRECT FIELD-ORIENTED CONTROL OF SIX-PHASE INDUCTION MOTOR '2016Fellow, IEEE 'Modeling and Control of Six-Phase Symmetrical Induction Machine Under Fault Condition Due to Open Phases 'IEEE TRANSACTIONS ON INDUSTRIAL ELECTRONICS, VOL. 55, NO. 5, MAY 2008

[13] Daniel Nahum Zmood, Student Member, IEEE and Donald Grahame Holmes, Member, IEEE IEEE 'Stationary Frame Current Regulation of PWM Inverters With Zero SteadyState Error' TRANSACTIONS ON POWER ELECTRONICS, VOL. 18, NO. 3, MAY 2003

[14] M.J. Duran1, I. Gonzalez-Prieto1, N. Rios1, F. Barrero2 'A Simple, Fast and Robust Openphase Fault Detection Technique for Six-phase Induction Motor Drives' 2017

[15] G.K. Singh *, V. Pant, Y.P. Singh 'Voltage source inverter driven multi-phase induction machine' Corresponding author. Tel.: +91-133285070; fax: +91-1332-73560. E-mail address: gksngfee@iitr.ernet.in (G.K. Singh).0045-7906/\$ - see front matter _ 2003 Elsevier Ltd. All rights reserved. doi:10.1016/S0045-7906(03)00036-3

[16] Federico Barrero, Senior Member, IEEE, Manuel R. Arahal, Member, IEEE, RaúlGregor,
Sergio Toral, Senior Member, IEEE, and Mario J. Durán 'One-Step Modulation Predictive Current Control Method for the Asymmetrical Dual Three-Phase Induction Machine 'IEEE TRANSACTIONS ON INDUSTRIAL ELECTRONICS, VOL. 56, NO. 6, JUNE 2009

[17] Reza Kianinezhad, BabakNahid-Mobarakeh, Member, IEEE, LotfiBaghli,FranckBetin, Member, IEEE, and Gérard-André Capolino 


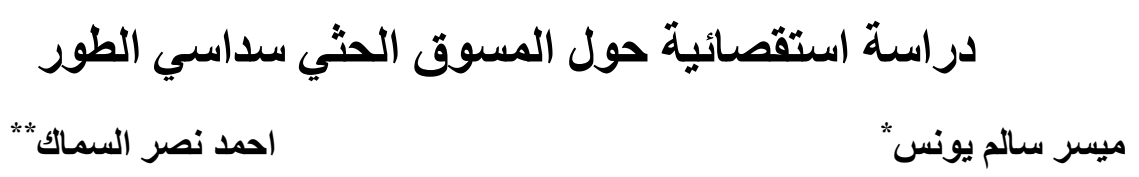

ahmed_alsammak@uomosul.edu.iq

myasaralattar@uomosul.edu.iq

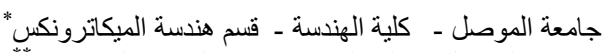

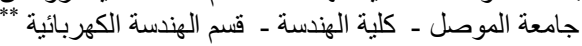

بتناول البحث مواضيع مختلفة قدمها باحثون سابقون حول المدرك الحثي سداسي الطور منها طرق مختلفة لتحليل الدائرة المكافئة للمحرك

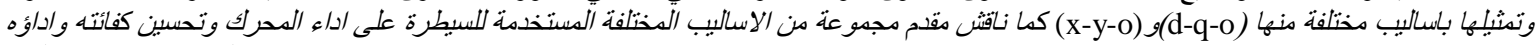

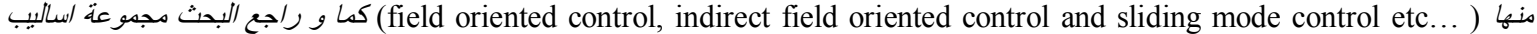
quasi voltage generation,puls width modulation , and space vector puls ( مختلفة لتوليب الفولتية المسوقة للمحرك بالاعتماد على تفنيات . (width modulation etc 